\title{
Evaluation of Public Compliance with Health Protocols on A New Normal Era During the COVID-19 Pandemic in Indonesia
}

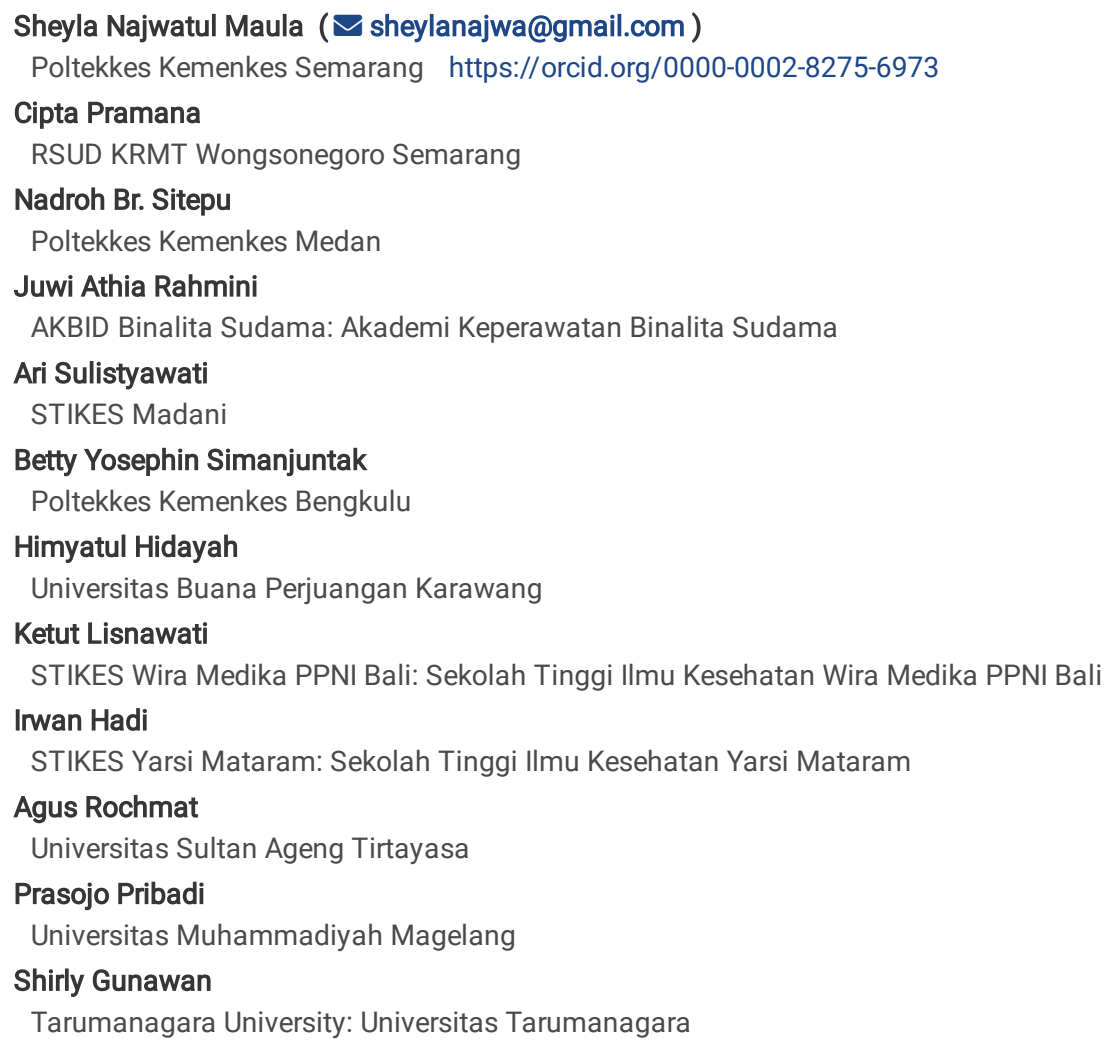




\section{Abstract}

\section{Background:}

Clinical manifestations of COVID-19 are characterized by mild upper respiratory tract infections, non-life-threatening lower respiratory tract infections, and life-threatening pneumonia with acute respiratory distress syndrome. Higher intensity exposure causes complications and even death especially in individuals with comorbidities such as diabetes, cardiovascular disease, cancer, and other metabolic diseases. Health protocols are already in place, but their implementation is not yet optimum and consequently directly affects the increase sharply in the number of cases which are increasing day by day, down to the normal era. This study aims to evaluate community adherence to health protocols during the new normal in Indonesia.

\section{Methods:}

This research was conducted using media technology in the google form questionnaire. The number of respondents was 533 people. There are 35 questions from processes to the final outcome of health protocol components and necessary conditions to achieve indicators of evaluation result. The inferential statistical test used in this study is Chi-Square.

\section{Results:}

Results reveal significant relationships between education and social distancing and the habit of washing hands, with $p$ value $<0.05$. The same results were also found for relationships between occupation and frequency of body temperature measurement, the use of masks, and the habit of washing hands. However, it was found that relationships between education and frequency of body temperature measurement, the use of masks, and the habit of washing were insignificant, with $p$ value>0.05. The same results were also found for relationships between occupation and social distancing.

\section{Conclusion:}

Evaluation of community compliance with health protocols show some improvement as has been proven with significant relationships of some variables. Nonetheless, variables such as relationships between education and body temperature measurement and the use of masks, as well as relationships between occupation and social distancing still require further evaluation.

\section{Background}

The novel coronavirus (2019-nCoV) is a new type of virus originating from China that causes respiratory tract disease. This virus is in the same family as the viruses that cause MERS and SARS, but has wider range of transmission. Coronaviruses (COVID-19) are the largest group of viruses in the Nidovirales family which includes Coronaviridae, Arteriviridae, Mesoniviridae, and Roniviridae. Coronaviridae is divided into two subfamilies, namely Coronavirinae and Toroviranae. Coronavirinae has four genera, namely alpha, beta, gamma and delta COVID-19. From all viruses in the Nidovirales sequence, there are differences in the number, type, and size of protein structures that specifically contain the RNA genome, up to $33.5 \mathrm{~kb}$ of genome. These differences lead to significant changes in the structure and morphology of nucleocapsids and virions [1]

The World Health Organization officially declared the COVID-19 infection disease a pandemic on March 11, 2020. COVID-19 was first identified in the city of Wuhan in China on 7 January 2020. The spread of this virus is quite fast and right across the world. In Indonesia, the first confirmed case of COVID-19 was on March 2, 2020. In the city of Semarang, cases of confirmed COVID-19 were first reported on 17 March 2020 [2] and cases of COVID-19 in infants were first reported on 3 April 2020 [3] By 15 January 2021, there is a total of 870,000 confirmed positive cases with a death toll of 25,246 in Indonesia. This global emergency prompted the government to issue health protocols in order to prevent and overcome further transmissions of COVID-19 [4].

Health protocols are steps taken to break the chain of COVID-19 transmission. These include wearing a mask, washing hands with soap, keeping distance, staying away from crowds, and staying at home. Unfortunately, the pre-determined preventive measures cannot be applied by the whole community. This condition can lead to further emergencies with higher severity as well as critical conditions due to the accumulation of comorbid conditions and even death. Results of the research on public's response to actively participate in preventing the spread of COVID-19 by complying with government calls to implement health protocols show that it is not yet optimum. In spite of efforts from the government through its Ministries to disseminate health protocol education via various mass and social media, members of the community have not optimally implemented health protocols during the new normal era. Therefore, community compliance with health protocols in carrying out daily activities needs to be evaluated [5].

On 3 January 2021, the COVID-19 Task Force reported less than 60\% compliance with health protocols in 99 districts/municipalities in Indonesia. One of the indicators of the report is the use of masks in public places. The lowest for this practice is at restaurants (64.54\%), sports venues (77.94\%), and the streets (80.20\%). In terms of distancing, 109 districts/municipalities still records less than $60 \%$ compliance. The use of masks and distancing has decreased from September to December, with $83.67 \%$ people wearing masks in September, and down to only $39.51 \%$ in December. This study aims to evaluate the compliance of the Indonesian people to the health protocol during the new normal. Comprehensive results from this study can be used as indicators in follow-up and preventive efforts, in terms of health protocols at the community level to break the chain of COVID-19 transmission [6].

This research has been approved by the health research ethics committee with permit number 01.996 / HREC / Health Polytechnic of the Ministry of Health Medan 2020. Analysis was conducted by comparing two or more indicators of variance through inferential tests to obtain differences from various indicators. Results from various variants show significant relationships between education and social distancing, the habit of washing hands. Significant 
results also show significant relationships between occupation and frequency of body temperature measurement, the use of masks, and the habit of washing hands, with both sets of relationships show $p$-value $(<0.05)$.

\section{Methods}

This research was conducted by utilizing technology media using a google form questionnaire. It contains the purpose of research as an evaluation measure to prevent and handle the COVID-19 pandemic in the new normal era. It also contains various questions and the use of both univariate and bivariate analyzes. The univariate analysis includes an overview of respondents, respondent behavior during the pandemic, workplace and environmental readiness in facing the new normal era during the COVID-19 pandemic. Meanwhile, bivariate analysis includes the relationships among variables presented. There are 35 questions ranging from process to outcome of health protocols and other related conditions to obtain evaluation result indicators.

Responds gathered from the questionnaire then underwent computerized statistical tests. In turn, results of computation and analysis are presented in tables and diagrams. The statistical test used is inferential Chi-Square, which was then further tested using non-parametric statistical analysis technique to compare two or more groups.

\section{Results}

Univariate analysis work on research subjects' characteristics. It reveals description of frequency, mean and standard deviation. Univariate analyses carried out include on general description of respondents, behavior of respondents during the pandemic, and readiness to face the new normal era (Table 1-5).

Normality test was carried out before bivariate analysis by calculating skewness. Bivariate test on the proportion of two or more groups that are related to categorical variables (Chi-Square test). Results of bivariate analysis was then compared to results of research measurements, and further analysis was carried out to describeresults both between variables and between groups. Variables in univariate analysis include age, education level and occupation, with the aim of describing variables based on age group. An overview of the respondents' characteristics from univariate is given in the following table.

1. General description of respondents

Table 1

Frequency distribution of respondents characteristics $(n=506)$

\begin{tabular}{|lll|}
\hline Characteristics & Frequency (f) & Percentage (\%) \\
\hline Gender & 144 & 28.5 \\
Female & 362 & 71.5 \\
Age & & \\
15-19 & 40 & 7.9 \\
20-24 & 70 & 13.8 \\
25-29 & 51 & 10.1 \\
$30-34$ & 97 & 19.2 \\
35-39 & 69 & 13.6 \\
40-44 & 74 & 14.6 \\
$45-49$ & 47 & 9.3 \\
50-54 & 41 & 8.1 \\
55-59 & 14 & 2.8 \\
60 and over & 3 & 0.6 \\
Educational Background & 74 & 35.0 \\
High school & 3 & 14.6 \\
Diploma 1 & 153 & 0.6 \\
Diploma 3 & 177 & 30.2 \\
Diploma 4/ Stratum I & 85 & \\
Stratum II/Master & 14 & \\
Stratum III/Doctorate & & \\
\hline
\end{tabular}


Table 1 shows that female respondents are predominantly within the productive age of 30-34 and most of them have Diploma 4/Bachelor degree. 
Table 2

Frequency distribution of respondent job information characteristics $(n=506)$

\begin{tabular}{|c|c|c|}
\hline Job Information & Frequency (f) & Percentage (\%) \\
\hline Occupation & 176 & 34.8 \\
\hline 1. Private company/cooperative/foundation employees & 192 & 37.9 \\
\hline 2. Civil servants/army/police officers & 138 & 27.3 \\
\hline \multicolumn{3}{|l|}{ 3. Entrepreneurs } \\
\hline Job shade & 238 & 47.0 \\
\hline 1. Government & 102 & 20.2 \\
\hline 2. Individual or independent & 166 & 32.8 \\
\hline \multicolumn{3}{|l|}{ 3. Private } \\
\hline Position qualification level & 131 & 25.9 \\
\hline 1. Undefined & 232 & 45.8 \\
\hline 2. Operators/implementers & 46 & 9.1 \\
\hline 3. Lower management (equivalent to echelon $4 b$ to $4 a$ ) & 77 & 15.2 \\
\hline 4. Middle management (equivalent to echelon $3 b$ to $2 b$ ) & 20 & 4.0 \\
\hline \multicolumn{3}{|l|}{ 5. Top management (equivalent to echelon 2a to 1a) } \\
\hline How to work & 95 & 18.8 \\
\hline 1. Work from home & 109 & 21.5 \\
\hline 2. Work from home or work in the office (in turns) & 302 & 59.7 \\
\hline \multicolumn{3}{|l|}{ 3. Work in the office } \\
\hline Division of work time (last 2 weeks) & 211 & 41.7 \\
\hline 1. Work in shifts & 295 & 58.3 \\
\hline \multicolumn{3}{|l|}{ 2. Without shift arrangements } \\
\hline Business Fields & 5 & 1.0 \\
\hline 1. Administration, government, defense, and social security & 1 & 0.2 \\
\hline 2. Water supply, waste management, waste, and recycling & 3 & 0.6 \\
\hline 3. Electricity and gas supply & 6 & 1.2 \\
\hline 4. Accommodation and food \&drink provision & 2 & 0.4 \\
\hline 5. Wholesale and retail trade, car repair and maintenance & 2 & 0.4 \\
\hline 6. Mining and quarrying & 8 & 1.6 \\
\hline 7. Agriculture, forestry, and fisheries & 4 & 0.8 \\
\hline 8. Transportation and warehousing & 5 & 1.0 \\
\hline 9. Processing industry & 3 & 0.6 \\
\hline 10. Information and communication & 244 & 48.2 \\
\hline 11. Health services and social activities & 4 & 0.8 \\
\hline 12. Financial and insurance & 81 & 16.0 \\
\hline 13. Educational & 2 & 0.4 \\
\hline 14. Corporate services & 4 & 0.8 \\
\hline 15. Construction and real estate & 132 & 26.1 \\
\hline 16. Other services & & \\
\hline
\end{tabular}




\begin{tabular}{|c|c|c|}
\hline Job Information & Frequency (f) & Percentage (\%) \\
\hline Work Location (Province) & 33 & 6.5 \\
\hline 1. Bali & 8 & 1.6 \\
\hline 2. East Kalimantan & 3 & 0.6 \\
\hline 3. South Kalimantan & 10 & 2.0 \\
\hline 4. West Kalimantan & 6 & 1.2 \\
\hline 5. Lampung & 14 & 2.8 \\
\hline 6. West Nusa Tenggara & 3 & 0.6 \\
\hline 7. East Nusa Tenggara & 4 & 0.8 \\
\hline 8. Papua & 10 & 2.0 \\
\hline 9. Riau & 3 & 0.6 \\
\hline 10. South Sulawesi & 9 & 1.8 \\
\hline 11. Central Sulawesi & 11 & 2.2 \\
\hline 12. Banten & 18 & 3.6 \\
\hline 13. Southeast Sulawesi & 7 & 1.4 \\
\hline 14. West Sumatera & 4 & 0.8 \\
\hline 15. South Sumatera & 130 & 25.7 \\
\hline 16. North Sumatera & 7 & 1.4 \\
\hline 17. Bengkulu & 45 & 8.9 \\
\hline 18. DKI Jakarta & 30 & 5.9 \\
\hline 19. West Java & 75 & 14.8 \\
\hline 20. Central Java & 9 & 1.8 \\
\hline 21. East Java & 26 & 5.1 \\
\hline 22. Yogyakarta & 3 & 0.6 \\
\hline 23. Central Kalimantan & 38 & 7.5 \\
\hline 24. Others & & \\
\hline
\end{tabular}

Table 2 shows that most respondents are civil servants/army/police officers who work for the government and predominantly qualified as operators/implementers. During the new normal period, most of them work in the office without shift arrangements. Most respondents are working in the field of health services and activities in North Sumatra.

2. Behavior of respondents during the pandemic 
Table 3

Frequency distribution of respondents behavior at work during pandemic

\begin{tabular}{|c|c|c|}
\hline Behavior at work & Frequency (f) & Percentage (\%) \\
\hline Frequency of body temperature measurements in a day while at work & 127 & 25.1 \\
\hline None & 235 & 46.4 \\
\hline 1 time & 86 & 17.0 \\
\hline 2 times & 58 & 11.5 \\
\hline \multicolumn{3}{|l|}{3 times or more } \\
\hline Use of masks during work & 24 & 4.7 \\
\hline$<50 \%$ of the working time & 30 & 5.9 \\
\hline $50-74 \%$ of the working time & 108 & 21.3 \\
\hline $75-99 \%$ of the working time & 344 & 68.0 \\
\hline \multicolumn{3}{|l|}{$100 \%$ of the working time } \\
\hline Average distance to colleagues/customers while at work & 172 & 34.0 \\
\hline Less than 1 meter & 286 & 56.5 \\
\hline 2 meters & 48 & 9.5 \\
\hline \multicolumn{3}{|l|}{3 metersor more } \\
\hline Frequency of washing hands with soap/hand sanitizer during work hours & 4 & 0.8 \\
\hline Never & 53 & 10.5 \\
\hline 1 to 2 times & 151 & 29.8 \\
\hline 3 to 4 times & 298 & 58.9 \\
\hline More than 5 times & & \\
\hline
\end{tabular}

Table 3 shows that behavior of respondents at work during the new normal and reveals that body temperature measurement is mostly done once. It also shows that most of respondents use mask (100\%) at work, most of respondents maintain an average distance of 2 meters from colleagues/consumer. It also reveals that most respondents wash hands more than 5 times during work hours. These results show that most respondents adhere to health protocols during the new normal period, whilst some others still neglecting them. 
Table 4

Frequency distribution of respondents' behavior related to compliance with daily health protocols during the new normal period $(n=506)$

\begin{tabular}{|lll|}
\hline Daily behavior & Frequency (f) & Percentage (\%) \\
\hline Keeping up with the latest information about COVID-19 & 10 & 2.0 \\
Never & 28 & 5.5 \\
Rarely & 150 & 29.6 \\
Sometimes & 150 & 29.6 \\
Often & 168 & 33.2 \\
Always & & \\
Using a mask in daily activities & 3 & 0.6 \\
Never & 6 & 1.2 \\
Rarely & 29 & 5.7 \\
Sometimes & 91 & 18.0 \\
Often & 377 & 74.5 \\
Always & & \\
Observing social distancing and physical distancing & 2 & 0.4 \\
Never & 11 & 2.2 \\
Rarely & 92 & 18.2 \\
Sometimes & 195 & 38.5 \\
Often & 206 & 40.7 \\
Always & & \\
\hline
\end{tabular}

Table 4 shows daily behavior of respondents during the new normal period and it also reveals that most respondents always keep themselves up to date with the latest information about COVID-19, most respondents always use masks in their daily activities and they always do social distancing and physical distancing when interacting during the pandemic.

3. Workplace and environmental readiness in facing the new normal era during the COVID-19 pandemic 
Table 5

Frequency distribution of workplace and environmental readiness in the face of the new normal era during the COVID-19 pandemic

\begin{tabular}{|c|c|c|}
\hline The readiness of the workplace & Frequency (f) & Percentage (\%) \\
\hline Health protocols are applicable in the workplace & 499 & 98.6 \\
\hline Yes & 7 & 1.4 \\
\hline \multicolumn{3}{|l|}{ No } \\
\hline Health insurance is available in the workplace & 407 & 80.4 \\
\hline Yes & 99 & 19.6 \\
\hline \multicolumn{3}{|l|}{ No } \\
\hline In the last 4 weeks, disinfectants have been used in the workplace & 347 & 68.6 \\
\hline Yes & 159 & 31.4 \\
\hline \multicolumn{3}{|l|}{ No } \\
\hline Hand sanitizer is available in the workplace & 15 & 3.0 \\
\hline Not available & 12 & 2.4 \\
\hline Less available & 47 & 9.3 \\
\hline Sufficient available & 251 & 49.6 \\
\hline Available & 181 & 35.8 \\
\hline \multicolumn{3}{|l|}{ Highly available } \\
\hline Sink and hand soap are available in the workplace & 9 & 1.8 \\
\hline Not available & 12 & 2.4 \\
\hline Less available & 37 & 7.3 \\
\hline Sufficient available & 282 & 55.7 \\
\hline Available & 166 & 32.8 \\
\hline Highly available & & \\
\hline
\end{tabular}

Table 5 shows the readiness of the workplace in facing the new normal period and it also reveals that almost all workplaces provide health protocols and most of them provide health insurance for workers. In the last 4 weeks, there has been disinfectant spraying routines at work, while hand sanitizers, sinks, and hand soaps are predominantly available.

4. Compliance to COVID-19 health protocols relates to respondents' education and occupation 
Table 6

Relationship of COVID-19 health protocol compliance with education and employment

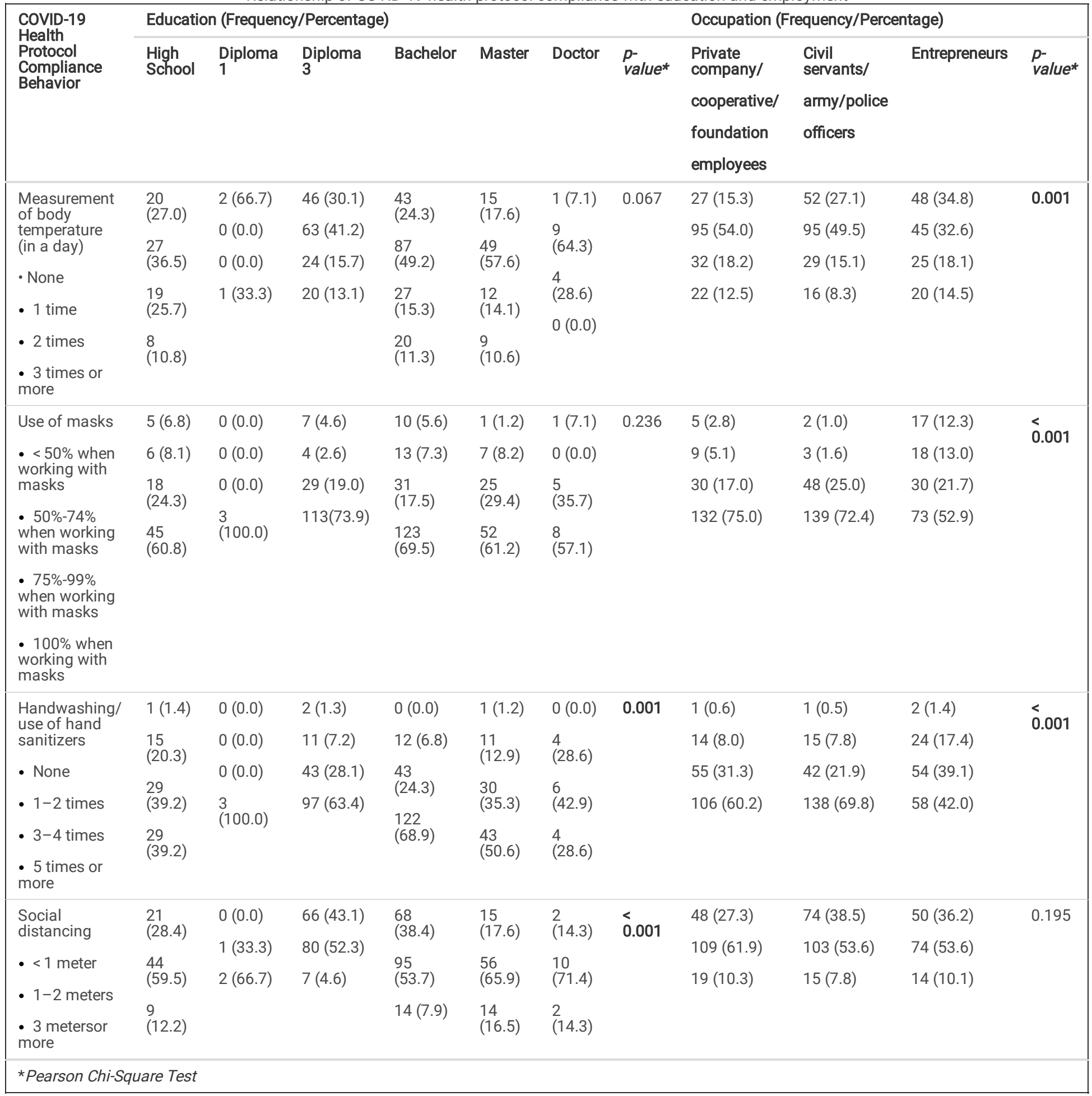

Table 6 shows that compliance to COVID-19 health protocols includes temperature measurement, the use of masks, the habit of washing hands/using hand sanitizers, and social distancing relates to respondents' education and occupation. Results of statistical tests show that the habit of washing hands/using hand sanitizers and social distancing are significantly related to educational background $(p<a)$. This is supported by data distribution which shows that higher level of education lead to improved frequency of washing hands by 5 or more times a day. These results also show that social distancing is practiced by respondents of all educational background, by maintaining a distance of 1-2 meters from their colleagues. However, results also reveal insignificant relationships between education and body temperature measurement and the use of masks, with $p$-value $(p>a)$.

Based on the respondents' job, results from statistical tests show that body temperature measurement, the use of masks, and the habit of washing hands/using hand sanitizers significantly relates to respondents' occupation $(p<a)$. Respondents who work as civil servants/army/police officers and those who work in private companies/cooperatives/foundations undergo more body temperature measurements, use masks more wash hands more, 
compared to those who are self-employed. Some indicators in this study show that occupation and social distancing does not have significant relationship $(p=0.195>a=0.05)$.

\section{Discussion}

Results of measurement analysis of variable variations using chi-square statistical test show significant relationships between educational background and social distancing. The same also applies for the relationship between educational background and the habit of washing hands. Higher education leads to more compliant behavior, in this case, practicing social distancing and washing hands. The mindset of properly educated people plays important role in shaping their attitude and behavior.

Based on the results of research, the processes involved in an interception, including the anatomy and function of neural and non-neural pathways, diseases and disorders, manipulation and intervention, and predictive modeling. In detail, this process explains how we can feel and interact with the outside world. On the sensory side, what is known as 'exteroception' includes the primary sensory system, vision, audition, smell, taste, and the ability of the nervous system to represent the internal world of humans [7]. The results further explained that the polarity of transcranial direct current stimulation (tDCS) was shown to modulate subjective, neuronal, and neuroendocrine responses and influence behavior [8]. Behavior is also an indicator with the highest frequency of the spread of COVID-19 in China. It is associated with higher education, perceived severity, negative emotions, concern and trust in government media during the outbreak of COVID-19 [9].

Results also show significant relationships between occupation and frequency of measuring body temperature, the use of masks, and the habit of washing hands. Respondents working as civil servants/army/policeofficers and those working in private companies/cooperatives/foundations are more likely to measure body temperature, wear masks and wash hands, compared to independent workers. Different results from both sets of workers (civil servants and private sector employees) are due to different nature of their responsibilities, that in turn, lead to different knowledge and mindset. At the beginning of the emergence of the coronavirus until it was finally declared a pandemic, the level of knowledge about COVID-19 was very low, but over time, the community became more open and could learn through various sources about the conditions in their surroundings, as is the case with people in Pakistan and the USA [10].

Results also reveal no significant relationships between education and frequency of measuring body temperature at work. It may be due to the fact that health protocol during a pandemic has been part the system that everyone must adhere to, regardless of their status. Measurement of body temperature in the workplace still requires further evaluation concerning important indicators such as the use of thermometers for optimal temperature measurement using tympanic thermometers (more invasive with the measurement of core temperatures such as rectal temperature, esophagus, and pulmonary artery catheter). Other indicators include type and calibration process that is appropriate and precise, distance of measurement, environment where measurement is taking place (atmospheric attenuation, ambient temperature, environmental humidity), limit values in identifying temperatures in different places and relationship between skin surface temperature and core temperature. Commonly used infrared thermometer can help identify hyperpyrexia (oral temperature $38.0 \mathrm{c}$ ) in $59 \%$ of cases, while no hyperpyrexia is estimated at $90 \%$ because some of these measurements often lead to false negatives. Infrared thermometer and the inner canthus of the eye (medium and palpebral slit tip) are recommended to estimate core temperature [11, 12].

Results also further reveal no significant relationships between education level and the use of masks. The dominant use of masks is cloth masks, which are less effective, because surgical masks are intended for health workers [13, 14]. Most respondents know that cloth masks are not very effective (88.2\%) and that surgical masks cannot be reused. This means that knowledge does not necessarily translates to proper practices [15].

Several recent studies stated that $23.1 \%$ of 1,096 respondents do not have good knowledge of COVID-19 prevention, $50.8 \%$ of respondents have negative attitudes towards COVID-19 and $27.5 \%$ of respondents do not have good action against COVID-19 [16]. Another study stated that $17 \%$ of the 1,021 respondents have poor knowledge about COVID-19 prevention, and 29.7\% of respondents have poor behavior regarding COVID-19 prevention. This shows that good knowledge tends to lead to good behavior [17]. This condition can be influenced by the policy of wearing masks in public spaces which caused some controversy at the beginning of the pandemic [18]. The World Health Organization does not recommend routine use of masks as the prevention of exposure to Covid-19 in public spaces for healthy people [19]. Meanwhile, the CDC recommends the use of masks in public spaces routinely because, at the time of the pandemic, it is found that coronaviruses is transmitted by an infected person with no clinical symptoms [20].

Other results indicate no significant relationships between occupation and social distancing. All respondents, both working as civil servants/army/police officer and those working in private companies/cooperatives/foundations, as well as independent workers practice social distancing with similar average distance. Social distancing is part of the health protocols that must be observed during the pandemic and new normal. The goal is to maintain a safe distance to prevent transmission of coronaviruses from one person to another.

\section{Conclusion}

Evaluation results show that community adherence to health protocols has seen some improvements. Results from inferential test of variable variants reveal significant relationships between educational background and social distancing and the habit of washing hands. They also show significant relationships between occupation and body temperature measurement and the use of masks, as well as the habit of washing hands, with each variable having p-value $(<0.05)$. However, relationships between educational background and body temperature measurement and the use of masks, and relationships between occupation and social distancing still need further improvement as they show insignificant values. 


\section{Abbreviations}

CDC: Centers for Disease Control and Prevention, COVID-19: Coronavirus Disease 19, HREC: Health Research Ethics Committee, kb: kilobases, MERS: Middle East Respiratory Syndrome, RNA: Ribonucleic Acid, SARS: Severe Acute Respiratory Syndrome, tDCS: transcranial direct current stimulation, USA: United State of America

\section{Declarations}

Ethics approval and consent to participate

The study received health research etchical committee from Health Polytechnic of the Ministry of Health Medan, Indonesia with permit number 01.996 / HREC / Health Polytechnic of the Ministry of Health Medan 2020 and all participants provided consent to participate online. Especially for participants under 16 years of age, informed consent was obtained and strengthened from a parent or guardian

Consent for publication

Not applicable

Availability of data and materials

Not applicable

Competing interests

The authors declare that they have no competing interests.

Funding

No funding was obtained for this study

Authors' contributions

NBS and AS: Licensing of the Health Research Ethics Committee. SNM, CP, JAR, and BYS: Study conceptualization and design, data analysis, manuscript drafting and revision. HD, KL, IH, AR, and PP: Data collection and data entry. SNM, CP, and SG: Data analysis, reviewed, and edited the manuscript. All authors (SNM, CP, NBS, JAR, AS, BYS, HD, KL, IH, AR, PP, and SG) have agreed to authorship and order of authorship for this manuscript.

Acknowledgements

We would like to express gratitude to all participants for undertaking this survey

\section{References}

1. Maier HJ, Bickerton E, Britton P. Coronaviruses. Methods and protocols. 2015.

2. Pramana C, Herawati S, Santi N, Maryani LPES, Dachliana OR. The first case of COVID-19 in Semarang, Indonesia: A case report. Luh Putu Endyah Santi and Dachliana, Oktina Rachmi, The First Case of COVID-19 in Semarang, Indonesia: A Case Report (January 4, 2021$) .2021$.

3. Sumarni N, Dewiyanti L, Kusmanto MH, Pramana C. A Case of 2019 Novel Coronavirus Infection in a Preterm Infant with Severe Respiratory Failure (preprint). 2021.

4. Worldometers. COVID-19 Coronavirus Pandemic. 2020.

5. Buana DR. Analisis Perilaku Masyarakat Indonesia dalam Menghadapi Pandemi Virus Corona (Covid-19) dan Kiat Menjaga Kesejahteraan Jiwa. Salam: Jurnal Sosial dan Budaya Syar-i. 2020;7(3):217-26.

6. Hennida C, Saptari NO, Aristyaningsih IGAAR, Febrianto AS. Respons Negara Dan Institusi Global Terhadap Covid-19: Airlangga University Press; 2020.

7. Chen WG, Schloesser D, Arensdorf AM, Simmons JM, Cui C, Valentino R, et al. The emerging science of interoception: sensing, integrating, interpreting, and regulating signals within the self. Trends in neurosciences. 2021;44(1):3-16.

8. Gheorghe DA, Panouillères MT, Walsh ND. Investigating the effects of cerebellar transcranial direct current stimulation on saccadic adaptation and cortisol response. Cerebellum \& Ataxias. 2021;8(1):1-11.

9. Ning L, Niu J, Bi X, Yang C, Liu Z, Wu Q, et al. The impacts of knowledge, risk perception, emotion and information on citizens' protective behaviors during the outbreak of COVID-19: a cross-sectional study in China. BMC public health. 2020;20(1):1-12 
10. Ladiwala ZFR, Dhillon RA, Zahid I, Irfan O, Khan MS, Awan S, et al. Knowledge, attitude and perception of Pakistanis towards COVID-19; a large crosssectional survey. BMC public health. 2021;21(1):1-10.

11. Park DS. The invisible university is COVID-19 positive. Trends in Genetics. 2020.

12. Zhang L-P, Wang M, Wang Y, Zhu J, Zhang N. Focus on a 2019-novel coronavirus (SARS-CoV-2). Future Microbiology. 2020(0).

13. Eikenberry SE, Mancuso M, Iboi E, Phan T, Eikenberry K, Kuang Y, et al. To mask or not to mask: Modeling the potential for face mask use by the general public to curtail the COVID-19 pandemic. Infectious Disease Modelling. 2020.

14. Howard J, Huang A, Li Z, Tufekci Z, Zdimal V, van der Westhuizen H-M, et al. Face masks against COVID-19: an evidence review. 2020.

15. Allam M, Cai S, Ganesh S, Venkatesan M, Doodhwala S, Song Z, et al. COVID-19 diagnostics, tools, and prevention. Diagnostics. 2020;10(6):409.

16. Syakurah RA, Moudy J. Pengetahuan terkait usaha pencegahan Coronavirus Disease (COVID-19) di Indonesia. HIGEIA (Journal of Public Health Research and Development). 2020;4(3):333-46.

17. Utami RA, Mose RE, Martini M. Pengetahuan, Sikap dan Keterampilan Masyarakat dalam Pencegahan COVID-19 di DKI Jakarta. Jurnal Kesehatan Holistic. 2020;4(2):68-77.

18. Feng Y, Marchal T, Sperry T, Yi H. Influence of wind and relative humidity on the social distancing effectiveness to prevent COVID-19 airborne transmission: A numerical study. Journal of aerosol science. 2020:105585.

19. Organization WH. Advice on the use of masks in the context of COVID-19: interim guidance, 5 June 2020. World Health Organization, 2020.

20. Lazarus JV, Ratzan S, Palayew A, Billari FC, Binagwaho A, Kimball S, et al. COVID-SCORE: A global survey to assess public perceptions of government responses to COVID-19 (COVID-SCORE-10). PloS one. 2020;15(10):e0240011. 